\title{
COMPARATIVE ELECTROMAGNETIC AND QUASI-STATIC SIMULATIONS OF A SHORTPULSE PROPAGATION ALONG MICROSTRIP MEANDER DELAY LINES WITH DESIGN CONSTRAINTS
}

\author{
Pavel Orlov — Talgat Gazizov - Aleksander Zabolotsky *
}

\begin{abstract}
A numerical analysis of microstrip meander delay lines is considered. Results of quasi-static and electromagnetic simulations are given. It is shown that when increasing a number of turns and proportionally reducing their length, distortions of a pulse signal in the line are reduced. At the same time, despite structure's electrical width increase, the agreement between the results of quasi-static and electromagnetic analyses is improved. Thus, it is demonstrated that when designing the microstrip meander delay lines with minimal distortions, the quasi-static analysis is relevant.
\end{abstract}

K e y w ords: electromagnetic analysis, meander delay line, quasi-static approach, design constrains, simulation

\section{INTRODUCTION}

Trends of modern electronics devices development (decrease in dimensions, increase in the upper frequency of signal spectrum, etc.) lead to increase in package density and to the need for signals asynchrony minimization. In this regard, delay lines, particularly in the form of a meander, as the simplest structure, are widely used. However, crosstalk arises, and it can distort waveform and reduce delay time of a pulse propagating in the line [1] . There are different approaches to crosstalk level reduction, for example, use of guard traces [2], but it increases the area of meander lines. Meanwhile, it is often required to minimize the area of meander lines.

These factors lead to the need for numerical analysis of meander lines. Two approaches to the analysis are used: quasi-static and electromagnetic. The first approach is usually less consumptive but it is an approximation, as it is based on the telegraph equations, which are valid only for small electrical width of a structure. The second approach takes into account higher order modes but is more consumptive and requires more users' competencies [3] than the work with the quasi-static approach.

Electromagnetic analysis for one set of parameters of the microstrip meander delay line is presented in [4]. A similar analysis, but in the range of parameters, is made in [5]. Comparison between the electromagnetic and quasi-static analysis results and the experimental results obtained for the strip line is given in [6] . Comparison of the results obtained by three different numerical meth- ods for one set of microstrip line parameters is presented in [7]. These studies did not investigate applicability of the quasi-static analysis for the case of electrically wide structures, in particular, when delay time and area of the meander microstrip line are defined and it is necessary to minimize distortions of the pulse signal. Meanwhile, such a research is very important for design process because it will help to optimize both parameters and analysis process of the meander delay lines. The aim of this paper is to fill this gap.

\section{SIMULATION RESULTS}

Simulation of the meander lines (Fig. 1) was executed in the CST MWS and TALGAT systems without accounting the losses in conductors and dielectrics. In the CST MWS the combination of perfect boundary approximation with the Finite Integration Technique is used [8] . The transient solver allows to make full-wave 3D analysis for structures of various complexities. The TALGAT system is based on method of moment and allows to make $2 \mathrm{D}$ quasi-static analysis. The algorithm implemented in the system allows to calculate all elements of moment matrix by fully analytical formulae only, avoiding the timeconsuming and approximate numerical integration. It can be useful for effective calculation of capacitive matrix of two-dimensional systems of various complexities [9].

In the TALGAT system, the meander line structure was represented like $N$-conductor transmission line, with ends of the conductors connected respectively (see Fig. 2).

* Tomsk State University of Control Systems and Radioelectronics, Tomsk, 634050, Russian Federation, praetorian281@gmail.com (PO) 


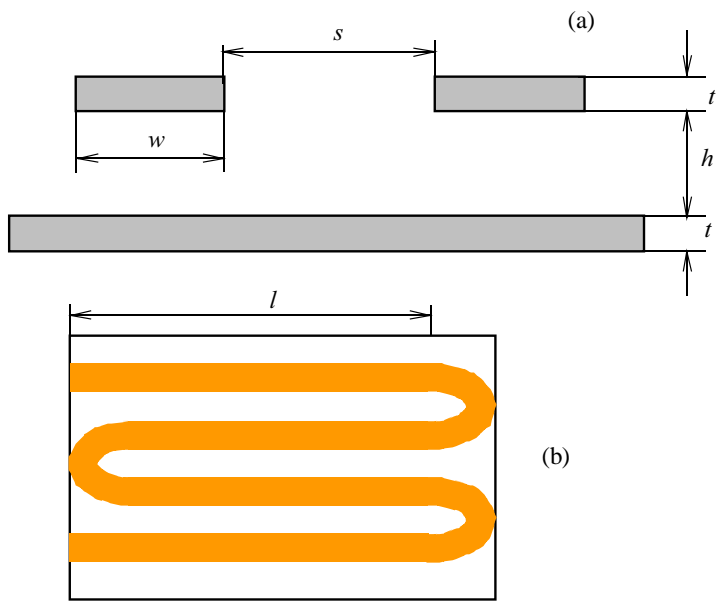

Fig. 1. Cross section of (a) - a turn model and (b) - top view of two turns

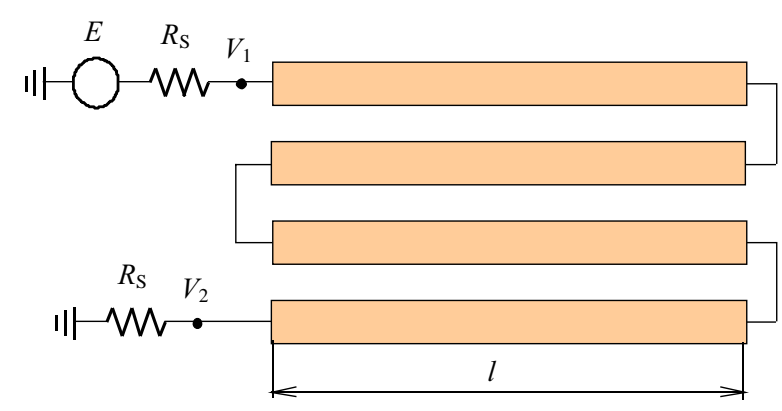

Fig. 2. Circuit diagram of a meander line model for quasi-static simulation with $N=4$

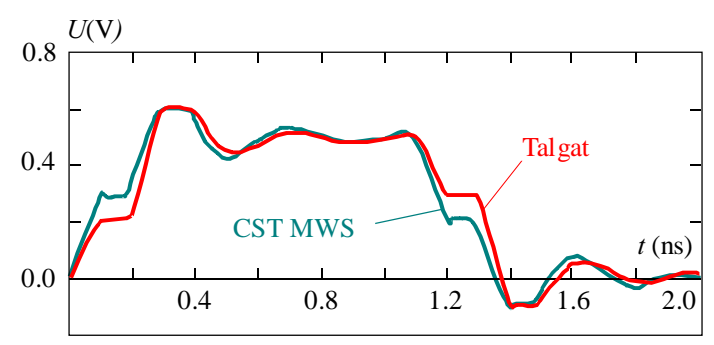

(a)

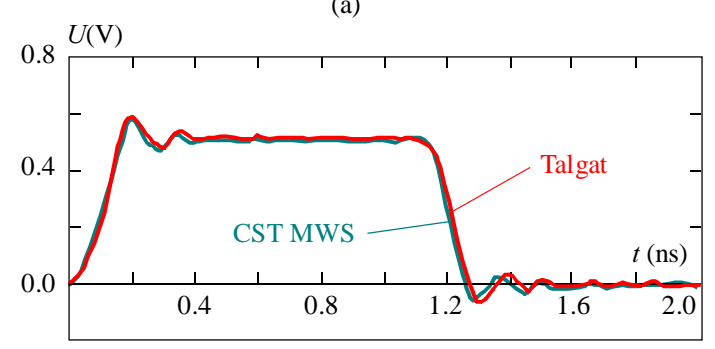

(c)
Table 1. Comparison of delay times at level 0.5 from Fig. 3

\begin{tabular}{|c|c|c|c|c|c|}
\hline$N$ & $\begin{array}{c}l \\
(\mathrm{~mm})\end{array}$ & $\begin{array}{r}T_{\mathrm{CST}} \\
(\mathrm{ps}) \\
\end{array}$ & $\begin{array}{c}T_{\text {TALGAT }} \\
(\mathrm{ps})\end{array}$ & $\begin{array}{l}\Delta T \\
(\mathrm{ps})\end{array}$ & $\begin{array}{c}100 \frac{\left|T_{\mathrm{CST}}-T_{\mathrm{TALGAT}}\right|}{T_{\mathrm{CST}}+T_{\mathrm{TALGAT}}} \\
(\%)\end{array}$ \\
\hline 2 & 20 & 87 & 206 & 119 & 40 \\
\hline 4 & 10 & 105 & 129 & 24 & 10 \\
\hline 8 & 5 & 93 & 109 & 16 & 8 \\
\hline 16 & 2.5 & 90 & 100 & 10 & 5 \\
\hline 32 & 1.25 & 89 & 104 & 15 & 8 \\
\hline
\end{tabular}

Structures with $N=2 ; 4 ; 8 ; 16 ; 32$, with the length $(l)$ of $20 ; 10 ; 5 ; 2.5 ; 1.25 \mathrm{~mm}$ were selected respectively. It allows to get electrically narrow and wide structures with a constant total length of conductors. The cross section of the analyzed structure is shown in Fig. 1a. Its parameters are: conductors thickness $(t)-35 \mu \mathrm{m}$, conductors width $(w)-50 \mu \mathrm{m}$, distance between conductors $(s)-50 \mu \mathrm{m}$, dielectric material $\left(\varepsilon_{r}=3.8\right)$; thickness $\left.(h)-2 \mathrm{~mm}\right)$. These parameters were chosen in such a way that a high level of electromagnetic coupling is generated between the half-turns, which maximizes the pulse distortions. The value of the resistance at the ends of the line was chosen under pseudomatching conditions as $205 \Omega$. A trapezoidal signal with EMF $1 \mathrm{~V}$ and duration of rise and fall $0.1 \mathrm{~ns}$, flat top - $1 \mathrm{~ns}$ was chosen as the excitation source. Waveforms at the output of the meander line are shown

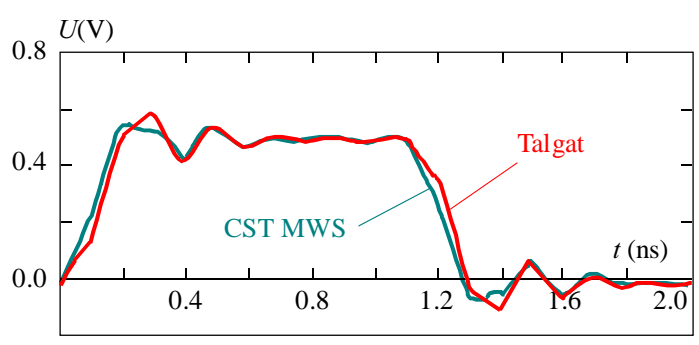

(b)

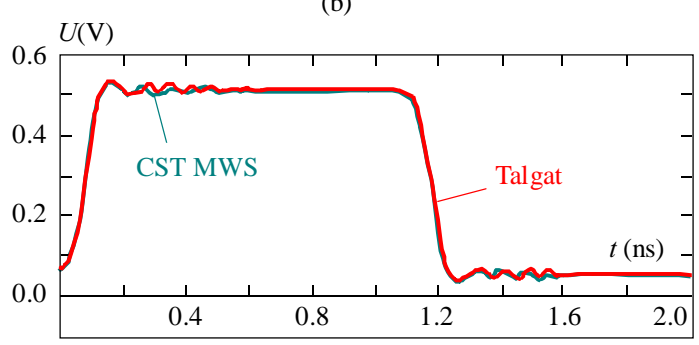

(d)

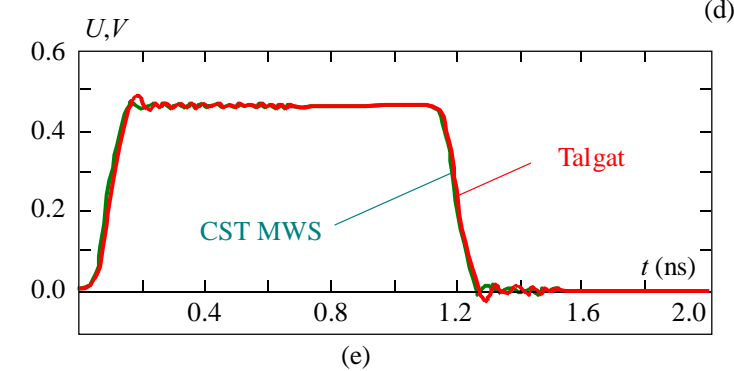

Fig. 3. Output waveforms of the examined structures with $N=($ a) $-2 ;($ b) -4 ; (c) -8 ; (d) -16 ; (e) -32 . 
in Fig. 3. Signal propagation delays at "0.5" level are presented in Tab. 1.

\section{CONCLUSIONS}

From these results it is clear that the waveform of the signal is subjected to distortions caused by electromagnetic coupling between the half-turns. However, the results of quasi-static and electromagnetic analysis showed good agreement: delays difference does not exceed $10 \%$, and only in case of $N=2$ it equals to $40 \%$ due to the difference of the near end crosstalk levels, that may be caused by neglect of edge effects at the ends of the halfturns in quasi-static analysis. For the upper frequency of signal spectrum $(10 \mathrm{GHz})$ the wavelength in vacuum equals to $3 \mathrm{~cm}$ and with the dielectric it is somewhat smaller. When $N=32$, structure width $(3.25 \mathrm{~mm})$ is more than $0.1 \lambda$, which can lead to incorrect results of quasi-static analysis. However, these results show the overall coincidence of quasi-static and electromagnetic analysis that allows us to conclude the correctness of the quasi-static analysis for structures of this type. It is worth noting, that with the same total length of lines the structures with larger $N$ give smaller waveform distortions.

Thus, a quasi-static analysis can be successfully used in the design of meander lines. This is especially important at the stage of optimization that requires repetitive calculations.

\section{Acknowledgment}

The work was supported by the contract $8.1802 .2014 / \mathrm{K}$ of the Russian Ministry of Education and Science.

\section{REFERENCES}

[1] WU, R. B.-CHAO, F. L. : Laddering Wave in Serpentine Delay Line, IEEE Trans. Components, Packag. Manuf. Technol. Part B, Adv. Packag 18 (1995), 644-650,, doi:10.1109/96.475270.

[2] SHIUE, G. H.-CHAO, C. Y.-WU, R. B. : Guard Trace Design for Improvement on Transient Waveforms and Eye Diagrams of Serpentine Delay Lines, IEEE Trans. Adv. Packag. 33 (2010), 1051-1060, doi:10.1109/TADVP.2010.2064165.
[3] BRUCE, A.: Importance and Process of Validation for All Levels of Modeling Problems, in: IEEE Int. Symp. EMC, 2009.

[4] TOPSAKAL, E.-VOLAKIS, J.: Finite Element Method for the Accurate Analysis of Delay Line Propagation Characteristics, 2003 IEEE Int. Symp. Electromagn. Compat. 2003. EMC '03., vol. 2, 2003, doi:10.1109/ICSMC2.2003.1429101.

[5] KABIRI, A.-HE, Q.-KERMANI, M. H.-RAMAHI, O. M. : Design of a Controllable Delay Line, IEEE Trans. Adv. Packag. 33 (2010), 1080-1087, doi:10.1109/TADVP.2010.2064166.

[6] RUBIN, B. J.-SINGH, B.: Study of Meander Line Delay in Circuit Boards, IEEE Trans. Microw. Theory Tech. 48 (2000), 1452-1460, doi:10.1109/22.868994

[7] BHOBE, A. U.-HOLLOWAY, C. L.-PIKET-MAY, M. : Meander Delay Line Challenge Problem: a Comparison using FDTD, FEM and MoM, 2001 IEEE EMC Int. Symp. Symp. Rec. Int. Symp. Electromagn. Compat. (Cat. No.01CH37161), vol. 2, 2001, doi:10.1109/ISEMC.2001.950479.

[8] The Finite Integration Technique, (n.d.). https://www.cst.com/Products/CSTmws/FIT.

[9] GAZIZOV, T. R.: Analytic Expressions for MOM Calculation of Capacitance Matrix of Two Dimensional System of conductors and Dielectrics Having Arbitrarily Oriented Boundaries, 2001 IEEE EMC Int. Symp. Symp. Rec. Int. Symp. Electromagn. Compat. (Cat. No.01CH37161), vol. 1, 2001, doi:10.1109/ISEMC.2001.950576.

Received 28 August 2015

Pavel Evgenievich Orlov was born in 1986. He received the the Engineering degree and $\mathrm{PhD}$ degree from Tomsk State University of Control Systems and Radioelectronics, Tomsk, Russia in 2008 and 2013, respectively. His research interest is electromagnetic compatibility. is the author or coauthor of 50 scientific papers, including 3 books.

Talgat Rashitovich Gazizov was born in 1963. He received the Engineering degree, the $\mathrm{PhD}$ degree, and the DSc degree from Tomsk State University of Control Systems and Radioelectronics, Tomsk, Russia, in 1985, 1999, and 2010, respectively. His current research interests includes signal integrity problem. He is the author or coauthor of 260 scientific papers, including 11 books.

Alexander Mikhailovich Zabolotsky was born in 1982 . He received the Engineering degree and the $\mathrm{PhD}$ degree from Tomsk State University of Control Systems and Radioelectronics (TUSUR), Tomsk, Russia, in 2004 and 2010, respectively. He is the author or coauthor of 172 scientific papers, including 7 books. 